\title{
Q Fever with Clinical Features Resembling Systemic Lupus Erythematosus
}

\author{
Hiroto Ohguchi, Yasuhiko Hirabayashi, Takao Kodera, Tomonori Ishii, \\ Yasuhiko Munakata and Takeshi Sasaki
}

\begin{abstract}
A 23-year-old woman with prolonged fever, rash, and pericarditis associated with high titers of antinuclear, anti-Sm, and anti-RNP antibodies was suspected of having systemic lupus erythematosus (SLE). However, we also considered infectious diseases, particularly $\mathrm{Q}$ fever, as the C-reactive protein level was elevated and the patient reported contact with zoo animals around two weeks before the onset. The condition responded rapidly to administration of minocycline; symptoms resolved without using steroids. Thereafter, no recurrence of the illness was observed. Titer of Coxiella burnetii antibody was high and the illness was accordingly diagnosed as acute $\mathrm{Q}$ fever rather than SLE.
\end{abstract}

Key words: Coxiella burnetii, autoantibody, collagen disease

(DOI: 10.2169/internalmedicine.45.1382)

\section{Introduction}

Q fever is a zoonosis with a worldwide distribution caused by Coxiella burnetii (C. burnetii), a strict intracellular bacterium that lives in host phagocytic cells $(1,2)$. The common sources of human infection are farm animals and pets such as cattle, goats, sheep, cats, and dogs. The infected mammals shed the desiccation-resistant organisms in urine, feces, and milk. Birth products in particular, including amniotic fluid and placenta, contain large numbers of the organism because reactivation of infection occurs in female mammals during pregnancy. The shed organisms can survive for long periods in the environment.

In humans, infection results from inhalation of contaminated aerosols or ingestion of unpasteurized milk from infected animals. The clinical signs of $Q$ fever vary greatly and are often subclinical. Acute $\mathrm{Q}$ fever most commonly presents as a self-limited flu-like syndrome, pneumonia or hepatitis. However, cases of meningitis, pericarditis, myocarditis, and rash are also reported (3). Moreover, autoantibodies are frequently found during the course of $\mathrm{Q}$ fever (1). Therefore, some cases may occasionally meet the criteria for autoimmune diseases. We report herein a case of acute $\mathrm{Q}$ fever with clinical features resembling systemic lupus erythematosus (SLE), successfully treated with minocycline.

\section{Case Report}

A 23-year-old Japanese woman had been in good health until mid-May 2003, when she developed a rash and high grade fever (Fig. 1). The rash initially had a periorbital distribution and then spread across the face. No history of seizures, erythema, photosensitivity, Raynaud's phenomenon, oral ulceration, dry eye, dry mouth, or arthralgia was reported. She had not taken oral contraceptives, and was not pregnant. She was not an intravenous drug abuser. Although the patient did not drink unpasteurized milk, she had come into contact with cats, dogs, and sheep at a zoo at the end of the previous month. Laboratory tests revealed a high titer of antinuclear antibodies and urinary protein was tracepositive. White blood cell count was $4,100 / \mu l$ and C-reactive protein (CRP) level was $3.5 \mathrm{mg} / \mathrm{dl}$. Blood cultures showed no growth. The patient had failed to respond to empirical antibiotic therapy with panipenem/cilastatin and clindamycin.

On May 27, 2003, when referred to our hospital, the pa-

Department of Rheumatology and Hematology, Graduate School of Medicine, Tohoku University, Sendai

Received for publication April 17, 2005; Accepted for publication December 16, 2005

Correspondence to Yasuhiko Hirabayashi, Department of Rheumatology and Hematology, Graduate School of Medicine, Tohoku University, 1-1 Seiryo-cho, Aoba-ku, Sendai, Miyagi 980-8574 


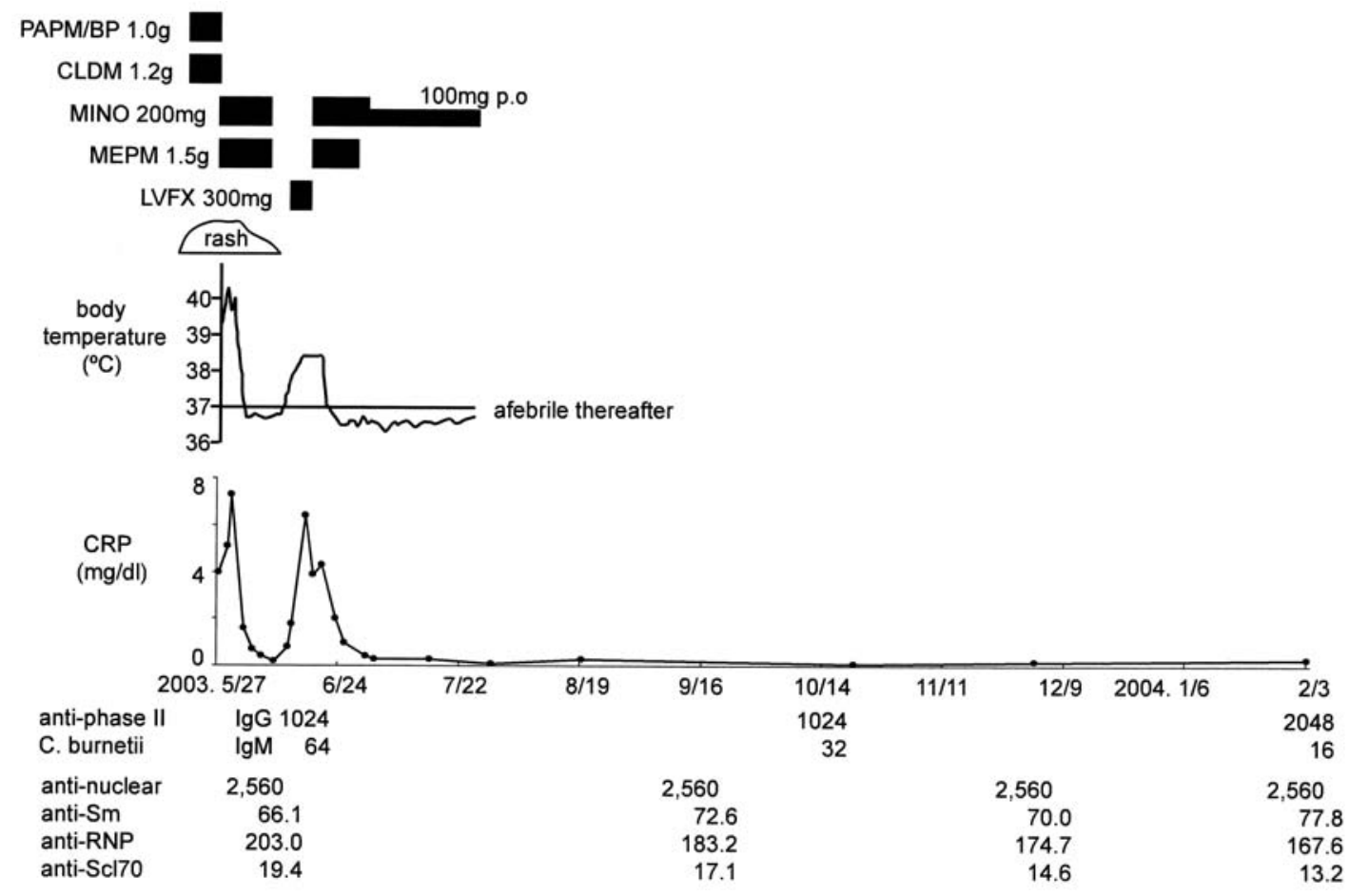

Figure 1. Clinical time course of the present patient. CLDM, clindamycin; CRP, C-reactive protein; LVFX, levofloxacin; MEPM, meropenem; MINO, minocycline; PAPM/BP, panipenem/ betamipron.

tient exhibited pyrexia $\left(38.0^{\circ} \mathrm{C}\right)$ and regular tachycardia $(106$ beats/min). Blood pressure was 113/68 mmHg. A macular erythematous rash was observed on the face, trunk, and extremities. The head, including the retinas, was otherwise normal. No abnormal findings were apparent in the chest or abdomen and no lymphadenopathy, leg edema, or joint swelling was found. Neurological examination was normal. Laboratory findings are shown in Table 1. Blood cultures again showed no growth. Electrocardiography showed generalized voltage reduction, and chest radiography revealed marked cardiomegaly (Fig. 2a). Echocardiography demonstrated a large pericardial effusion; however, neither cardiac tamponade nor endocarditis was evident.

The clinical and laboratory features (facial erythematous rash, pericarditis, anti-Sm antibody, and high titer of antinuclear antibody) appeared to fulfill the American College of Rheumatology 1997 revised criteria for the diagnosis of SLE; however, neither anti-dsDNA antibody nor hypocomplementemia was observed. The facial erythematous rash was neither butterfly-shaped nor discoid. It was macular with an indistinct border. Moreover, high CRP levels and high fever with chills suggested infection, despite the lack of obvious focus of infection. We suspected $\mathrm{Q}$ fever from the negative blood cultures, lack of response to antibiotic therapy with panipenem/cilastatin and clindamycin, and the history of contact with animals. Since the patient's condition had deteriorated, we commenced antibiotic therapy with minocycline (200 mg/day, intravenously) and meropenem (1.5 g/day, intravenously) although the diagnosis had yet to be confirmed. Antibiotic therapy appeared successful, as the fe- ver subsided within 2 days and the clinical condition improved considerably. The cutaneous rash disappeared and the pericardial effusion also decreased (Fig. 2b). Ten days after finishing a 12-day course of this therapy, the patient again developed fever; however, this rapidly subsided on resumption of these agents. At that time, titers of anti- $C$. burnetii phase II IgM and IgG antibodies, which were evaluated by an indirect immunofluorescence assay after absorption of rheumatoid factor activity, were 1:64 and 1:1024, respectively, indicating recent $\mathrm{Q}$ fever infection. Minocycline (200 mg/day) was therefore administered intravenously for 2 weeks and then orally (100 mg/day) for an additional 4 weeks. Follow-up serological studies 9 months after the onset of disease revealed that titers of antinuclear, anti-Sm, and anti-RNP antibodies remained elevated, but that titers of anti-C. burnetii phase II IgM and IgG antibodies were 1:16 and 1:2048, respectively (Fig. 1). The patient has remained asymptomatic during follow-up.

\section{Discussion}

At the onset of the disease, the clinical and laboratory profile resembled SLE, particularly with respect to the variety of autoantibodies expressed. However, symptoms responded rapidly to administration of minocycline without steroids being required and no recurrence of the illness was observed thereafter. Therefore, SLE could be ruled out. In acute Q fever, titers of phase II IgM and IgG antibodies are usually more than 50 and 200 , respectively $(1,2)$. In the present case, as titers of these antibodies were 1:64 and 1: 
Table 1. Laboratory Findings on Admission

\begin{tabular}{|c|c|c|c|}
\hline Urinalysis & & BUN (mg/dl) & 7 \\
\hline Protein & $\cdot$ & $\mathrm{Cr}(\mathrm{mg} / \mathrm{dl})$ & 0.5 \\
\hline Sugar & $\cdot$ & $\mathrm{UA}(\mathrm{mg} / \mathrm{dl})$ & 2.9 \\
\hline \multirow[t]{2}{*}{ Occult blood } & $\cdot$ & $\mathrm{Na}(\mathrm{mEq} / \mathrm{L})$ & 138 \\
\hline & & $\mathrm{K}(\mathrm{mEq} / \mathrm{L})$ & 3.5 \\
\hline $\operatorname{ESR}(\mathrm{mm} / \mathrm{h})$ & 63 & $\mathrm{Cl}(\mathrm{mEq} / \mathrm{L})$ & 99 \\
\hline \multirow{2}{*}{$\mathrm{CRP}$ (mg/dl) } & 4.4 & & \\
\hline & & $\mathrm{IgG}(\mathrm{mg} / \mathrm{dl})$ & 2,372 \\
\hline WBC $(/ \mu 1)$ & 5,400 & $\operatorname{IgA}(\mathrm{mg} / \mathrm{dl})$ & 331 \\
\hline Seg. (\%) & 65 & $\mathrm{IgM}(\mathrm{mg} / \mathrm{dl})$ & 123 \\
\hline Stab. (\%) & 15 & $\mathrm{C} 3(\mathrm{mg} / \mathrm{dl})$ & 124 \\
\hline Eosi. (\%) & 0 & $\mathrm{C} 4(\mathrm{mg} / \mathrm{dl})$ & 22.7 \\
\hline Baso. (\%) & 0 & $\mathrm{CH} 50(\mathrm{U} / \mathrm{ml})$ & 53.1 \\
\hline Ly. $(\%)$ & 13 & $\mathrm{IC}(\mathrm{C} 1 \mathrm{q})(<3.0 \mu \mathrm{g} / \mathrm{ml})$ & 2.1 \\
\hline Mono. (\%) & 7 & ANA $(x)$ & 2,560 \\
\hline $\mathrm{RBC}\left(\times 10^{4} / \mu \mathrm{l}\right)$ & 402 & $\mathrm{RF}(<20 \mathrm{IU} / \mathrm{ml})$ & 44.1 \\
\hline $\mathrm{Hb}(\mathrm{g} / \mathrm{dl})$ & 11.1 & Anti-dsDNA $(<12 \mathrm{IU} / \mathrm{ml})$ & 6.0 \\
\hline $\mathrm{Ht}(\%)$ & 34.2 & Anti-RNP $(<14.9 \mathrm{U} / \mathrm{ml})$ & 203.0 \\
\hline \multirow{2}{*}{$\operatorname{PLT}\left(x 10^{4} / \mu \mathrm{l}\right)$} & 31.9 & Anti-cardiolipin $(<9.9 \mathrm{U} / \mathrm{ml})$ & 8.3 \\
\hline & & Anti-Sm $(<5 \mathrm{U} / \mathrm{ml})$ & 66.1 \\
\hline PT $(\%)$ & 87.0 & Anti-SS-A $(<7 \mathrm{U} / \mathrm{ml})$ & 1.8 \\
\hline $\operatorname{APTT}(\mathrm{s})$ & 37.6 & Anti-SS-B (<10 U/ml) & 7.9 \\
\hline $\mathrm{Fib}(\mathrm{mg} / \mathrm{dl})$ & 421.0 & Anti-Sel70 $(<15.9)$ & 19.4 \\
\hline $\mathrm{FDP}(\mathrm{mg} / \mathrm{ml})$ & 12.3 & Anti-Jo-1 (<18 index) & 5 \\
\hline \multirow[t]{2}{*}{ D-dimer $(<0.3 \mathrm{mg} / \mathrm{ml})$} & 4.4 & C-ANCA $(<3.5 \mathrm{U} / \mathrm{ml})$ & 0.1 \\
\hline & & P-ANCA $(<9 \mathrm{U} / \mathrm{ml})$ & 0.7 \\
\hline $\mathrm{T} \cdot \mathrm{Bil}(\mathrm{mg} / \mathrm{dl})$ & 0.5 & Lupus anticoagulant $(1.3 \mathrm{sec})$ & 1.13 \\
\hline AST (IU/L) & 47 & Coombs & $\cdot$ \\
\hline ALT (IU/L) & 19 & RPR & - \\
\hline LDH (IU/) & 756 & endotoxin $(<4 \mathrm{pg} / \mathrm{ml})$ & $<1$ \\
\hline ALP (IU/L) & 154 & B-D-glucan $(<10 \mathrm{pg} / \mathrm{ml})$ & 4 \\
\hline YGTP (IU/L) & 30 & HBs Ag & $\cdot$ \\
\hline $\mathrm{ChE}(\mathrm{IU} / \mathrm{L})$ & 196 & HCV Ab $(<0.9)$ & 0.2 \\
\hline CK (IU/L) & 55 & B19 $\operatorname{IgM}(<0.7)$ & 0.2 \\
\hline $\mathrm{TP}(\mathrm{g} / \mathrm{dl})$ & 7.4 & CMV antigenemia & $\cdot$ \\
\hline $\mathrm{Alb}(\mathrm{g} / \mathrm{dl})$ & 3.3 & & \\
\hline \multicolumn{4}{|c|}{$\begin{array}{l}\text { ESR, erythrocyte sedimentation rate; CRP, C-reactive protein; WBC, white blood cells; RBC, red } \\
\text { blood cells; PLT, platelet; PT, prothrombin time; APTT, activated partial thromboplastin time; Fib, } \\
\text { fibrinogen; FDP, fibrin degradation product; TAT, thrombin-antithrombin complex; TM, } \\
\text { thrombomodulin, T-Bil, total bilirubin, AST, aspartate aminotransferase; ALT, alanine } \\
\text { aminotransferase; LDH, lactate dehydrogenase; ALP, alkaline phosphatase; } \gamma \text { GTP, } \\
\text { rglutamyl-transpeptidase; ChE, cholinesterase; TP, total protein; Alb, albumin; CK, creatine } \\
\text { kinase; BUN, blood urea nitrogen; Cr, creatinine; UA, uric acid; Ig, immunoglobulin; CH50, 50\% } \\
\text { hemolytic complement activity; ANA, antinuclear antibodies; RF, rheumatoid factor; ANCA, } \\
\text { antineutrophil cytoplasmic antibodies; RPR, rapid plasma reagin test; HBsAg, hepatitis B surface } \\
\text { antigen; HCV Ab, hepatitis C virus antibody; CMV, cytomegalovirus. }\end{array}$} \\
\hline
\end{tabular}

1024, respectively, a diagnosis of acute $Q$ fever was made.

In acute infection, a self-limited flu-like syndrome is the most common manifestation (3). Atypical pneumonia and hepatitis are also frequently observed. In addition, many other manifestations, such as aseptic meningitis, meningoencephalitis, pericarditis, and myocarditis, may occur (3-7). Endocarditis is a common manifestation in patients with previous valvular damage. Two epidemiological studies of C. burnetii infection revealed the frequency of pericarditis to be around 1\% (3); however, when serologic evaluation of sera from 141 patients with idiopathic pericarditis was per- formed, $C$. burnetii infection was suggested in 10 cases (7.1\%) (5). Since pericardiocentesis was not performed, $C$. burnetii was not identified in the pericardial fluid in the present case. To our knowledge, however, this is the first case of pericarditis associated with Q fever to be reported in Japan. In contrast to other rickettsioses, C. burnetii infections are not commonly associated with skin lesions (8). However, erythematous macules and papules can occur during the febrile episode as in the present case (9).

Another interesting finding in $\mathrm{Q}$ fever is the detection of autoantibodies such as anti-smooth muscle antibody, c- 
a

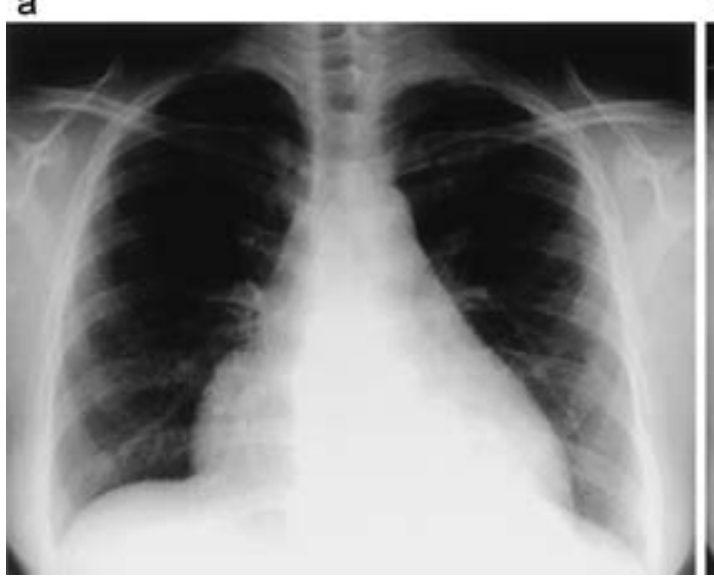

b

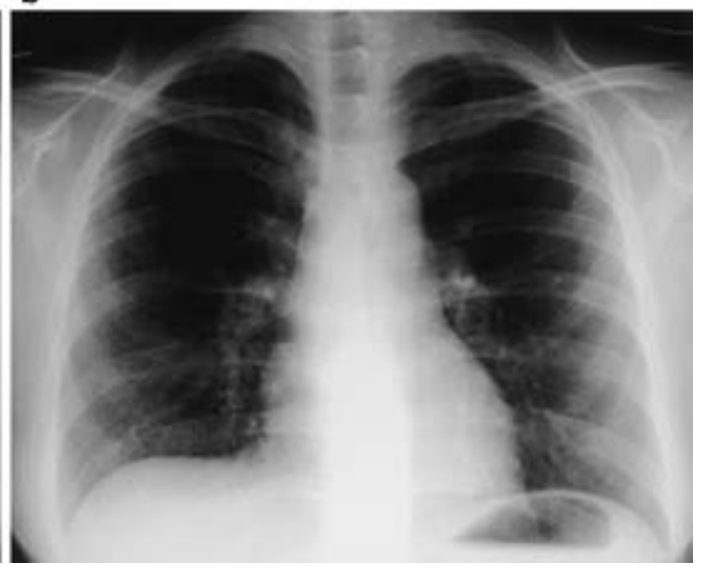

Figure 2. A: Chest radiograph taken on admission showed marked cardiomegaly. B: Two weeks after initiation of minocycline, chest radiograph revealed minimal effusion.

ANCA, and anti-cardiolipin antibody (10-13). The present case demonstrated high titers of antinuclear antibody, antiSm and anti-RNP antibodies that have not yet described in $\mathrm{Q}$ fever. The mechanism causing the production of autoantibodies is unknown.

In summary, this case emphasizes the importance of careful evaluation of each manifestation, even in the presence of disease-specific autoantibodies. We therefore recommend considering $\mathrm{Q}$ fever in the differential diagnosis of prolonged fever when blood cultures are negative and the patient has had recent contact with animals.

We would like to thank Miyagi Prefectural Institute of Public Health and Environment for the measurement of anti-phase II antibodies.

\section{References}

1. Fournier PE, Marrie TJ, Raoult D. Diagnosis of Q fever. J Clin Microbiol 36: 1823-1834, 1998.

2. Maurin M, Raoult D. Q Fever. Clin Microbiol Rev 12: 518-553, 1999.

3. Raoult D, Tissot-Dupont H, Foucault C, et al. Q fever 1985-1998: Clinical and epidemiologic features of 1,383 infections. Medicine (Baltimore) 79: 109-123, 2000.

4. Bernit E, Pouget J, Janbon F, et al. Neurological involvement in acute Q fever: a report of 29 cases and review of the literature. Arch Intern Med 162: 693-700, 2002.

5. Levy PY, Corey R, Berger P, et al. Etiologic diagnosis of 204 pericardial effusions. Medicine (Baltimore) 82: 385-391, 2003.

6. Levy PY, Carrieri P, Raoult D. Coxiella burnetii pericarditis: report of 15 cases and review. Clin Infect Dis 29: 393-397, 1999.

7. Fournier PE, Etienne J, Harle JR, Habib G, Raoult D. Myocarditis, a rare but severe manifestation of $\mathrm{Q}$ fever: report of 8 cases and review of the literature. Clin Infect Dis 32: 1440-1447, 2001.
8. Boele van Hensbroek M, de Vries E, Dolan G, Schneeberger P. Rash and petechiae as presenting signs of $\mathrm{Q}$ fever. Pediatr Infect Dis 19: 358, 2000.

9. Tissot-Dupont H, Raoult D, Brouqui P, et al. Epidemiologic features and clinical presentation of acute Q fever in hospitalized patients: 323 French cases. Am J Med 93: 427-434, 1992.

10. Levy P, Raoult D, Razongles JJ. Q-fever and autoimmunity. Eur J Epidemiol 5: 447-453, 1989.

11. Garcia-Zamalloa A, Gurruchaga N, Montes M. Q fever and antineutrophil cytoplasmic antibodies. Am J Med 108: 687-688, 2000.

12. Ordi-Ros J, Selva-O'Callaghan A, Monegal-Ferran F, MonasterioAspiri Y, Juste-Sanchez C, Vilardell-Tarres M. Prevalence, significance and specificity of antibodies to phospholipids in Q fever. Clin Infect Dis 18: 213-218, 1994.

13. Wong RCW, Wilson R, Silcock R, Kratzing LM, Looke D. Unusual combination of positive $\operatorname{IgG}$ autoantibodies in acute Q-fever infection. Intern Med J 31: 432-435, 2001.

(C) 2006 The Japanese Society of Internal Medicine http://www.naika.or.jp/imindex.html 